\title{
An unusual acute onset hard and small volume epidural blood clotting after anterior cervical discectomy with tetraparetic neurological findings
}

\author{
Hadi SASANI $^{1}$ (D), Mehdi SASANI ${ }^{2}$ (D), Fahir OZER ${ }^{2}$ (iD) \\ ${ }^{1}$ Department of Radiology, School of Medicine, Tekirdag Namik Kemal University, Tekirdag, Turkey. \\ ${ }^{2}$ Department of Neurosurgery, School of Medicine, Koc University, Istanbul, Turkey.
}

Corresponding Author: Hadi SASANI

E-mail: hsasani@nku.edu.tr

Submitted: 05.02.2020 Accepted: 15.04.2021

\begin{abstract}
Anterior cervical discectomy and fusion (ACDF) is one of the most commonly used surgical method to treat a variety of disorders in the cervical spine. Although, the incidence of complication related to ACDF is low, hematomas can be confronted after surgery. We report a 52-year-old male patient presented with complaints of paraesthesia and sensory loss in the upper extremities. Magnetic resonance imaging (MRI) showed a large central-right paracentral protrusion resulting in narrowing of the spinal channel at the level of C5-C6 accompanied by spinal cord compression and bilateral foraminal stenosis. ACDF was performed at this level. Five hours after surgery, sudden onset paraesthesia and tetraparesis developed. Urgent cervical MRI depicted acute filling half of the discectomy cavity, compressing the dural sac and spinal cord. The patient underwent revision surgery and the symptoms improved postoperatively. The patient received conservative therapy and was discharged without any nerological problem. Despite being a rare condition, sudden onset of neurological symptoms such as tetraparesis after ACDF surgery should remind the presence of hematoma at the surgical site.

Keywords: Discectomy, Magnetic Resonance Imaging, Hematoma
\end{abstract}

\section{INTRODUCTION}

Anterior cervical discectomy and fusion (ACDF) were first described by Smith and Robinson in 1958 [1]. It is a gold standard treatment method for many degenerative cervical spine diseases including disc herniation, radiculopathy, myelopathy, instability caused by degeneration or trauma, infection and tumours [2]. It is a relatively easy, reliable method with minimal risk [3]. ACDF is a widely used treatment technique which includes decompression of neural elements and stabilization when necessary, either through an anterior, posterior or combined approach. The approach selection depends on the location of the compressive element, type of fracture or ligament injury and the overall alignment [4].

Although, the incidence of complication related to ACDF is low, problems such as neural injury (recurrent laryngeal, superior laryngeal, hypoglossal nerve), organ injuries (oesophagus, trachea, vertebral and carotid artery, spinal cord and nerve roots, hoarseness, wound infection, CSF leakage) and hematomas can be seen after surgery [4-6].

Complications may be fatal if airway is involved due to cervical swelling or a hematoma and bleeding in the epidural space that may result in neurologic injury after ACDF surgery [7]. Therefore, the immediate diagnosis is crucial.

In this paper, clinical and imaging findings of an epidural hematoma that developed shortly after the operation with sudden onset of neurological deterioration, are presented.

\section{CASE REPORT}

A 52-year-old male patient presented with right-sided upper extremity radiating pain, right-sided sensation loss and muscle weakness ongoing for the last six months in his right arm. The neurological examination revealed $2 / 5$ right biceps muscle weakness and paresthesia compatible with right C6 nerve root dermatomal zone. Cervical magnetic resonance imaging (MRI) examination showed a large central-right paracentral extrusion which compressed the right C6 nerve root. Upper extremity electromyography test demonstrated acute denervation on the right $\mathrm{C} 6$ nerve root. The patient underwent surgical treatment. Anterior cervical C5-C6 microdiscectomy with implantation of anterior interbody cage and demineralized bone matrix was performed to establish fusion. The duration of the surgery was

How to cite this article: Sasani H, Sasani M, Ozer F. An unusual acute onset hard and small volume epidural blood clotting after anterior cervical discectomy with tetraparetic neurological findings. Marmara Med J 2021; 34: 339-343, doi: 10.5472/marumj.1013491 
45 minutes with no bleeding and neural structure damage. The patient was followed in the recovery room for one hour postoperatively. Vital findings were in the physiologic rate. He was transferred to neurosurgery patient ward after final examination by anaesthesiologist. His situation was uneventful till the five hours postoperatively, but he had complaints of numbness in the whole body, feeling as radiating electricity and could not move his upper and lower extremities. The physical examination revealed tetrapareses (upper extremities 2/5, lower extremities 4/5 muscle weakness). He was urgently transferred to obtain the whole spinal MRI. There were no brain functional disorders.

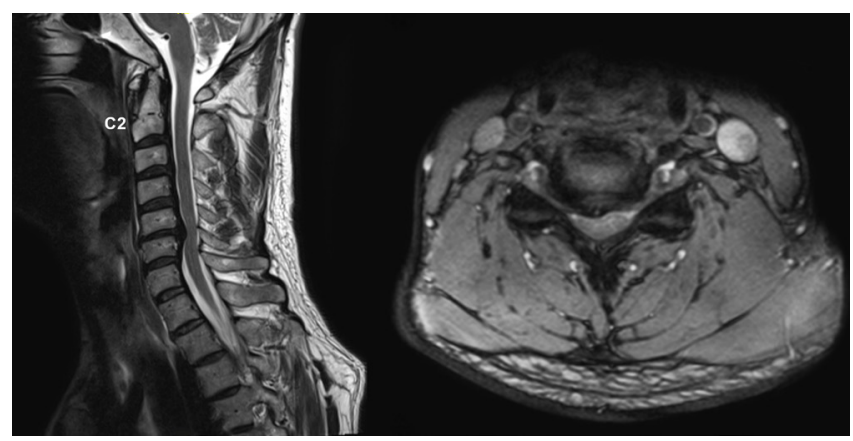

Figure 1. Sagittal and axial MRI images show a large central-right paracentral protrusion resulting in narrowing the spinal channel at the level of C5-C6 with posterior longitudinal ligament thickening and spinal cord compression. Bilateral foraminal stenosis at this level is present.

Urgent cervical MRI showed acute hematoma which was isointense in axial and sagittal T1-weighted images (WI), hyperintense in T2-WI; filling of the posterior space of the implanted cage and half of the discectomy cavity occupying more than half of the spinal canal in the C5-C6 level. It was measured $13.4 \times 6.3 \times 21 \mathrm{~mm}(0.886 \mathrm{ml})$ below one millilitre. This acute small hematoma compressed the dural sac and spinal cord at the level of C5-C6 (Figure 2). The patient was urgently transferred to operating room to evacuate haematoma. About $2 \mathrm{ml}$ hematoma was evacuated by aspiration and serum physiologic irrigation. The hematoma was very hard as if stone, which was not irrigable during the surgery. Haemostasis was gentelly done using haemostatic fibrin agents and bipolar cauterization. An interbody cage and demineralized bone matrix were re-implanted in C5-C6 intervertebral body space and then hemovac drainage catheter was placed. No active vascular or bone sponges focus of bleeding was found at revision surgery. In the postoperative first day, muscle weakness of the upper and lower extremities decreased and his condition improved.

Blood analysis of activated partial thromboplastin time (28 seconds), prothrombin time (10,8 seconds), international normalized ratio (INR: 0.98) and platelet count were in physiologic ranges. Further haematological studies were done in order to clarify the underlying pathology (von Willebrand factor deficiency, factor XII deficiency, haemophilia A), no remarkable finding was present.
Physical treatment protocol was performed by physical medicine physicians. Four days postoperatively, the ambulation of the patient was done with walker and cane. The patient fully recovered ten days postoperatively and discharged.

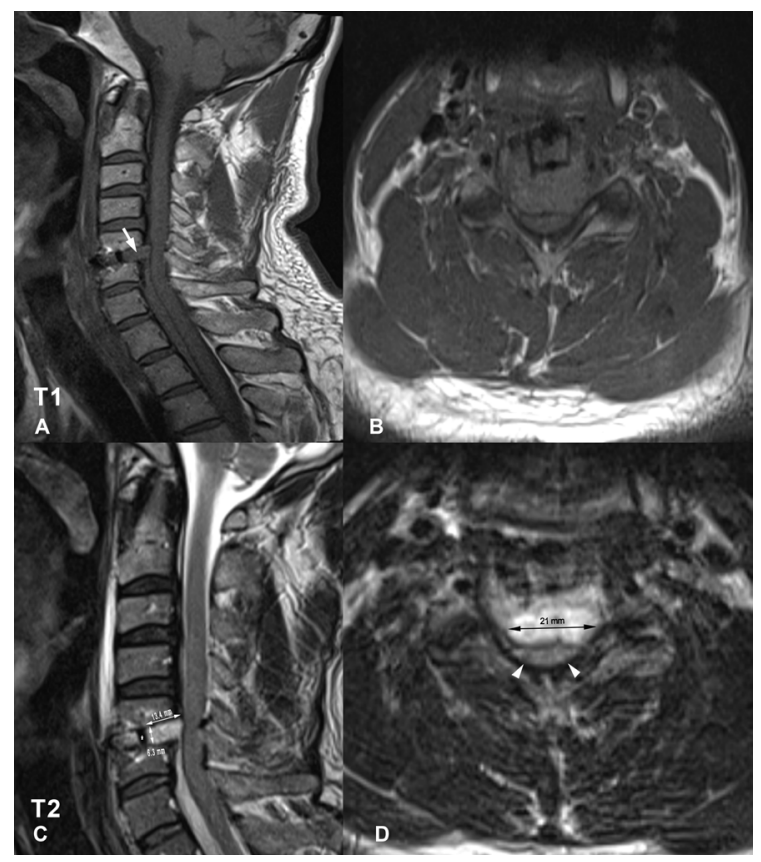

Figure 2. Obtained urgent MRI five hours later postoperatively. Sagittal and axial T1 and T2-weighted MR images demonstrate acute hematoma which fills the half of the discectomy cavity, compressing the dural sac and spinal cord at C5-C6 disc level. The hematoma is isointense on T1-WI and hyperintense on T2-WI (A,D arrows). Metallic cage is shown (C, asterisk). The size of the hematoma is shown in T2-weighted images $(C, D)$.

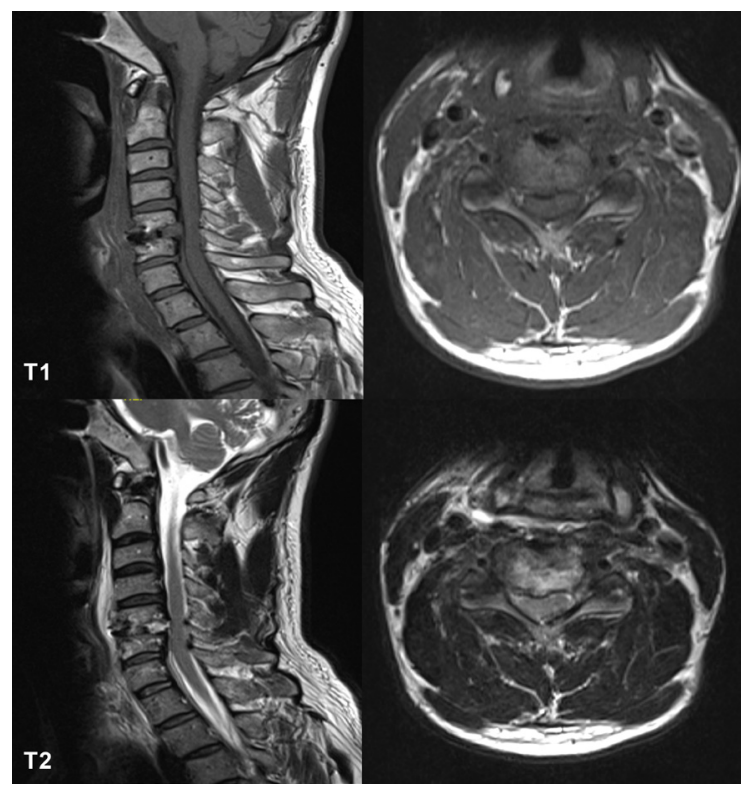

Figure 3. shows resorption of hematoma (postoperative 4th day). 


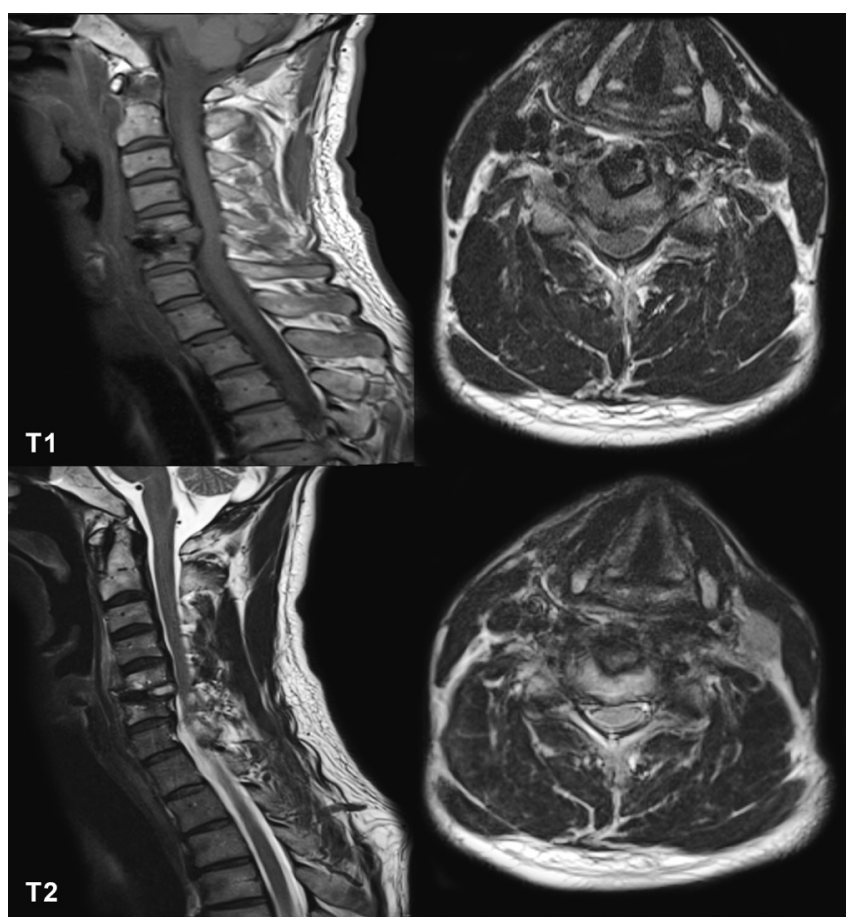

Figure 4. shows resorption of hematoma (postoperative 11th day).
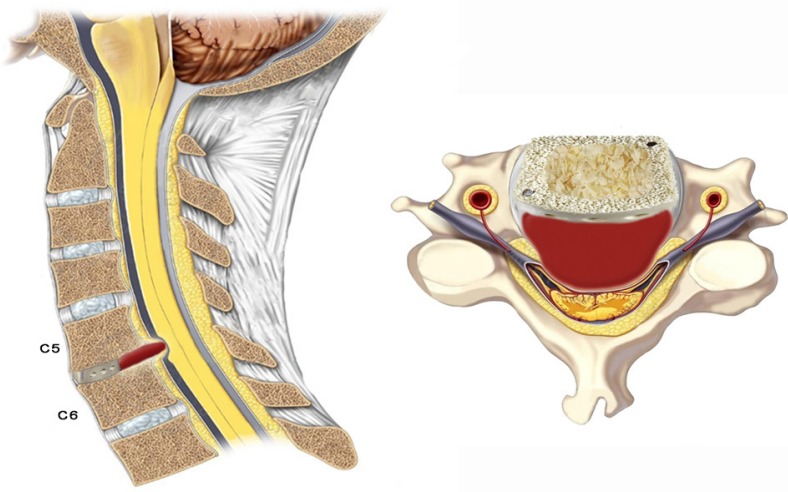

A

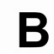

Figure 5. Illustration of the present case shows the hematoma at C5-C6 level compressing the dural sac and spinal cord. Metallic cage and inside demineralized bone matrix are shown.

\section{DISCUSSION}

The characteristic of current case is that after ACDF, neurological impairment and tetraparesis developed as a result of a rigid, immobile and stone-like small hematoma.

Possible complications such as epidural bleeding may be life threatening. Etiologic factors include trauma, invasive procedures (lumbar puncture, permanent spinal catheters, spine surgery), hematologic conditions (anticoagulation therapy, blood dyscrasias), infections, vascular malformations and pregnancy $[8,9]$. Studies revealed that all potentially life-threatening complications occur in the first six hours and patients should be discharged after the six hours observation period [10]. Among postoperative complications, dysphagia and hematoma are the two most common conditions which require intensive care during or after the operation. Some other complications such as airway oedema and respiratory involvement may peak at the second and third postoperative day [11].

The incidence of spinal epidural hematomas after surgery is very low $(0.24 \%)[6,8]$. Mean occurrence age of patients is between 50 - 80 years and the male dominant ratio is present (Male/ female ratio $=1.4 / 1)[12,13]$.

There are some case studies and case series of ACDF that reported the complications of ACDF as well as hematoma in the literature (Table I). Although, the overall complication rates were low $(1.71 \%)$ compared to other studies, in a metaanalysis study by Ben et al., four cases with hematoma were reported. They also mentioned dysphagia as the most common complication. Patients with hematoma were reported to have swelling, infection and pain [14]. This is an important point which indicates hematoma can occur early postoperatively, independent of complication rates.

Table I. Bleeding complication in outpatient surgery

\begin{tabular}{|l|l|c|c|l|}
\hline Author & $\begin{array}{l}\text { Total } \\
\text { Cases }\end{array}$ & $\begin{array}{l}\text { Cases with } \\
\text { complication }\end{array}$ & $\begin{array}{l}\text { Complication } \\
\text { rate (\%) }\end{array}$ & Complication \\
\hline $\begin{array}{l}\text { Adamson, et } \\
\text { al. [22] }\end{array}$ & 629 & 13 & 2.07 & Hematoma $(\mathrm{n}=1)$ \\
\hline $\begin{array}{l}\text { Lied, et al. } \\
\text { [23] }\end{array}$ & 96 & 4 & 4.17 & Hematoma $(\mathrm{n}=1)$ \\
\hline $\begin{array}{l}\text { Ben, et al. } \\
{[14]}\end{array}$ & 1693 & 29 & 1.71 & $\begin{array}{l}\text { Hematoma } \\
(\mathrm{n}=4)\end{array}$ \\
\hline
\end{tabular}

Yi et al., reported a series of postoperative epidural hematomas resulting in neurologic deterioration [6]. They retrospectively reviewed the database of 3720 cases over 7 years. Nine patients with postoperative neurologic in whom required surgical decompression were identified. They described the incidence of postoperative epidural hematoma as $0.24 \%$. After decompression, clinical outcome revealed complete recovery in 3 cases $(33.3 \%)$, incomplete recovery in 5 cases $(55.6 \%)$ and no change in 1 case $(11.1 \%)$. Factors increasing the risk of postoperative bleeding were defined as coagulopathy or anticoagulation therapy (44.4\%) and highly vascularized tumour $(33.3 \%)$. The time interval to evacuation of complete recovery group (29.3 hours) was shorter than incomplete recovery group (66.3 hours). Patients with coagulopathy and highly vascularized tumour were more vulnerable to develop spinal epidural hematoma. The postoperative outcome was related to the preoperative neurological deficit and the time interval 
to the decompression. In our case, the time of evacuation of hematoma after symptoms beginning to treatment was done less than six hours with complete recovery. There was no underlying pathology such as coagulopathy, tumour or AVM in our case.

Similar to our study Kim et al. [15] reported a case (36-yearold male) with sudden onset of cervical epidural bleeding which had developed within 5 minutes after surgery. The total surgery time was 108 minutes, and estimated blood loss was $50 \mathrm{cc}$. After surgery, five minutes later, he had developed tetraparesis. MRI showed an extensive epidural hematoma from C2 to T5, ventral to the spinal cord. The patient underwent an immediate revision operation and fresh blood was evacuated. On neurological exam after the revision ACDF, neurological symptoms had recovered. The post-op epidural hematoma had completely disappeared on follow-up imaging. In the article, the authors did not mention any finding about bleeding disorders or underlying pathology. Similar to this study as in our case, the hematoma was evacuated immediately, however, time of onset of symptoms in our case was 3 hours after surgery.

Jankowski et al. reported a 32-year-old female patient with huge acute cervical epidural hematoma as a complication developed after anterior cervical discectomy, resulting in complete loss of motor functions in the upper and lower limbs within 6 hours postoperatively. However, in our case, only a hematoma smaller than $1 \mathrm{ml}$ caused the same clinical findings [16].

Imaging plays important role in diagnosis. MRI is the first-line diagnostic modality in detection [17]. It is able to demonstrate the exact location, extension, distribution, size of the hematoma as well as its relation with spinal cord and the severity of the cord compression [18].

The hematoma shows isointense signal on T1-WI, high signal on T2-WI in acute stage (within 24 hours) and hyperintensity on both T1 - and T2 - weighted images in subacute stage (36 hours after symptom onset) [19,20]. Spinal angiography is not valuable particularly for those patients with progressive neurological deterioration [21].

In presented case, before the neurological symptoms occurred after the surgery in the earliest postoperative period, we thought it was a huge hematoma occupying the larger space as we wait in cervical surgeries on the base of literature knowledge and neck surgeons' experiences. However, cervical MRI study demonstrated only below $1 \mathrm{ml}$ of hematoma (Figure 2) resulting in the acute onset of tetrapareses. The cause of these symptoms was not due to the size of the hematoma, but was owing to its nature of the clot. The stone-like hematoma, compressed the Dural sac as well as spinal cord resulting in the symptoms. If the hematoma distributed homogenously and was not organised, the symptoms would have not prominent due to spread to larger area; therefore, destructive force of haematoma on spinal cord is decreased. Just despite of our case that it was very hard and cumulative haematoma as a bullet.

\section{Conclusion}

It is important to keep in mind that in a patient with sudden onset of neurological deterioration after ACDF surgery, the surgeon should consider the possibility of epidural hematoma at the surgical region and urgent MRI is required to clarify the pathology.

Conflict of interest: The authors have no conflicts of interest to declare.

Funding: No financial support was received for this study..

Authors' Contributions: HS.: Conception and design of the study. HS, MS. : Collection, analysis and interpretation of the data. FO.:Drafting the article and revising it critically for important intellectual content. Authors approved the final version of the article.

\section{REFERENCES}

[1] Denaro V, Di Martino A. Cervical spine surgery: an historical perspective. Clin Orthop Relat Res 2011;469:639-48. doi: 10.1007/s11999.010.1752-3.

[2] Hans P, Delleuze PP, Born JD, Bonhomme V. Epidural hematoma after cervical spine surgery. J Neurosurg Anesthesiol 2003;15:282-5. doi: 10.1097/00008.506.200307000-00020.

[3] Fowler SB, Anthony-Phillips P, Mehta D, Liebman K. Healthrelated quality of life in patients undergoing anterior cervical discectomy fusion. J Neurosci Nurs 2005;37:97-100.

[4] Cheung JP, Luk KD. Complications of anterior and posterior cervical spine surgery. Asian Spine J 2016;10:385-400. doi: 10.4184/asj.2016.10.2.385.

[5] Cabana F, Pointillart V, Vital J, Senegas J. Postoperative compressive spinal epidural hematomas. 15 cases and a review of the literature. Rev Chir Orthop Reparatrice Appar Mot 2000;86:335-45.

[6] Yi S, Yoon DH, Kim KN, Kim SH, Shin HC. Postoperative Spinal Epidural Hematoma: Risk Factor and Clinical Outcome. Yonsei Med J 2006;47:326-32. doi: 10.3349/ymj.2006.47.3.326.

[7] Fountas KN, Kapsalaki EZ, Nikolakakos LG, Smisson HF, Johnston KW, Grigorian AA, et al. Anterior cervical discectomy and fusion associated complications. Spine 2007;21:2310-7. doi: 10.1097/BRS.0b013e318154c57e.

[8] Aono H, Ohwada T, Hosono N, Tobimatsu H, Ariga K, Fuji $\mathrm{T}$, et al. Incidence of postoperative symptomatic epidural hematoma in spinal decompression surgery. J Neurosurg Spine 2011;15:202-5. doi:10.3171/2011.3.SPINE10716.

[9] Jang JW, Lee JK, Seo BR, Kim SH. Spontaneous resolution of tetraparesis because of postoperative cervical epidural hematoma. Spine J 2010;10:e1-5. doi: 10.1016/j. spinee.2010.09.021.

[10] Lied B, Sundseth J, Helseth E. Immediate (0-6 h), early (6$72 \mathrm{~h})$ and late $(>72 \mathrm{~h})$ complications after anterior cervical discectomy with fusion for cervical disc degeneration; discharge six hours after operation is feasible. Acta Neurochir 2008;150:111-8. doi: 10.1007/s00701.007.1472-y.

[11] Suk KS, Kim KT, Lee SH, Park SW. Prevertebral soft tissue swelling after anterior cervical discectomy and fusion with plate fixation. Int Orthop 2006;30:290-4. doi: 10.1007/ s00264.005.0072-9. 
[12] Groen RJ, Ponssen H. The spontaneous spinal epidural hematoma. A study of the etiology. J Neurol Sci 1990;98:12138. doi: 10.1016/0022-510x(90)90253-j.

[13] Groen RJ, van Alphen HA. Operative treatment of spontaneous spinal epidural hematomas: a study of the factor determining postoperative outcome. Neurosurgery 1996;39:494-509. doi: 10.1097/00006.123.199609000-00012.

[14] Ban D, Liu Y, Cao T, Feng S. Safety of outpatient anterior cervical discectomy and fusion: a systematic review and meta-analysis. Eur J Med Res 2016;21:34. doi: 10.1186/ s40001.016.0229-6.

[15] Kim JS, Kuh SU. Immediate Revision Surgery due to PostAnterior Cervical Discectomy and Fusion (ACDF) Spinal Epidural Hematoma. Korean J Spine 2012;9:111-3. doi: 10.14245/kjs.2012.9.2.111.

[16] JankowskiR,ZukielR,NowakS.Ostrykrwiaknadtwardówkowy w odcinku szyjnym kregosłupa-powikłanie po przedniej discektomii C5-C6, C5-C6. Opis przypadku [Acute cervical epidural hematoma as a complication of anterior cervical C5-C6 diskectomy. A case report]. Neurol Neurochir Pol. 2003;37:955-62. In Polish.

[17] Matsumura A, Namikawa T, Hashimoto R, Okamoto T, Yanagida I, Hoshi $M$, et al. Clinical management for spontaneous epidural hematoma: diagnosis and treatment. Spine J 2007;8:534-7. doi: 10.1016/j.spinee.2007.01.009.
[18] Liu Z, Jiao Q, Xu J, Wang X, Li S, You C. Spontaneous spinal epidural hematoma: analysis of 23 cases. Surg Neurol 2008;69:253-60; discussion 260. doi: 10.1016/j. surneu.2007.02.019.

[19] Lee DY, Lee SH. Cervicothoracic spinal epidural hematoma after anterior cervical spinal surgery. J Korean Neurosurg Soc 2010;48:541-3. doi: 10.3340/jkns.2010.48.6.541.

[20] Boukobza M, Haddar D, Boissonet M, Merland JJ. Spinal subdural haematoma: a study of three cases. Clin Radiol 2001;56:475-80. doi: 10.1053/crad.2000.0466.

[21] Qiu W, Sun W, Guo C, Wu Z, Ding M, Shen H. Diagnosis and microsurgery of symptomatic spontaneous spinal epidural hematoma. Ir J Med Sci 2011;180:241-5. doi: 10.1007/ s11845.010.0533-z.

[22] Adamson T, Godil SS, Mehrlich M, Mendenhall S, Asher AL, McGirt MJ. Anterior cervical discectomy and fusion in the outpatient ambulatory surgery setting compared with the inpatient hospital setting: analysis of 1000 consecutive cases. J Neurosurg Spine 2016;5:1-7. doi: 10.3171/2015.8.SPINE14284.

[23] Lied B, Rønning PA, Halvorsen CM, Ekseth K, Helseth E. Outpatient anterior cervical discectomy and fusion for cervical disk disease: a prospective consecutive series of 96 patients. Acta Neurol Scand 2013;127:31-7. doi: 10.1111/j.16000404.2012.01674.x. 